\title{
NATIVE SPEAKER AND NONNATIVE SPEAKER IDENTITIES IN REPAIR PRACTICES OF ENGLISH CONVERSATION
}

\author{
Eun Young Bae Department of Applied Linguistics, University of California, Los Angeles \\ ebae07@ucla.edu
}

Sun-Young Oh Department of English Education, Seoul National University

sunoh@snu.ac.kr

\begin{abstract}
Within the theoretical and methodological framework of Conversation Analysis, the present study explores the nature of the native speaker (NS) and nonnative speaker (NNS) identities in repair practices of English conversation. It has identified and analyzed in detail repair sequences in the data and has also conducted quantitative analyses in order to investigate the relationship between NS/NNS identities and repair practices. The results show that the categories of NS and NNS identities are social products that are invoked during and through the participants' ongoing interaction. First of all, the participants did not invariably make their NS/NNS identities relevant to their repair work; specifically, more than half of the repair practices were irrelevant to these identities. Secondly, when the participants' NS/NNS identities were made relevant to repair, both the NS and the NNS participants initiated repair in order to solve interactional problems that had resulted from the NNS participants' insufficient linguistic abilities. The participants' orientation to their NS/NNS identities was frequently triggered by the NNS participants' repair-initiation while the NS participants invoked these linguistic identities only in a limited range of interactional environments. The findings of this study provide a further empirical basis for arguing the importance of an emic approach to NS-NNS interactions and the potential to learn new vocabulary through repair.
\end{abstract}

KEY WORDS: conversation analysis, repair, identity, (non)native speaker

\section{INTRODUCTION}

Researchers in the field of Second Language Acquisition (SLA) recurrently resort to the categories of native speaker (NS) and nonnative speaker (NNS) when examining and interpreting second language (L2) speakers' behaviour. As noted by Firth and Wagner (1997) and Kurhila (2006), SLA researchers whose interest lies in L2 interaction have also tended to view the interlocutors as representatives of the NS/NNS categories and interpret their linguistic outcomes as reflecting these categories. Numerous studies on identity and social interaction in Conversation Analysis (CA) (e.g., Antaki \& Widdicombe, 1998; Benwell \& Stokoe, 2006; Speer \& Stokoe, 2011), however, have effectively demonstrated that identities such as gender and other social or institutional identities are not individuals' stable private properties but interactional achievements. These studies have pointed out that identities are made relevant by 
interlocutors through talk and are refreshed, negotiated, disputed, and challenged on a momentby-moment basis. In a similar vein, criticisms and concerns have been voiced over the dichotomous, static, and etic approaches to NS/NNS identities (e.g., Carroll, 2000; Firth \& Wagner, 1997; Markee \& Kasper, 2004; Pavlenko, 2002; Pennycook, 2001; Rampton, 1995). In particular, the potential relevance of the multiple social identities of the interlocutors to L2 interaction challenges the consistent application of the NS/NNS identities from the etic perspective. These new viewpoints on NS/NNS identities have triggered interest in exploring them as a product of social interaction, that is, as a social construct (e.g., Egbert, 2004; Egbert, Niebecker, \& Rezzara, 2004; Hosoda, 2006; Kasper, 2004; Kurhila, 2004, 2006; Park, 2007; Wong, 2000a, 2000b, 2005). Consistent with these current perspectives, this study attempts to explore the socio-interactional and dynamic nature of the NS/NNS identities by examining the relationship between the NS/NNS identities and repair practices in English conversation involving American NSs and Korean NNSs.

Repair is an orderly organization utilized by interlocutors to deal with all problems concerning speaking, hearing, and understanding talk (Schegloff, Jefferson, \& Sacks, 1977). In traditional SLA studies, repair practices tend to be frequently and pervasively interpreted with reference to the NNS participants' nonnativeness, that is, the NNS participants' insufficient and incomplete mastery of a target language (e.g., Bitchener, 1999; Gass \& Varonis, 1985; Pica, 1987; Pica, Holliday, Lewis, \& Morgenthaler, 1989; Varonis \& Gass, 1985). Unlike these studies in SLA, which treat the NS/NNS categories as self-evident, the present study subscribes to the view that considers the relevance of these identities as an object of inquiry. Some studies sharing this viewpoint recently examined the association between the NS/NNS identities and repair practices from a conversation-analytic perspective (e.g., Carroll, 2004; Hosoda, 2006; Kasper, 2004; Kurhila, 2004, 2006). It has been suggested that (other-) repair is a sequential environment in which 'differentially distributed linguistic knowledge' between NS and NNS participants, and thus NS/NNS identities, becomes relevant (Hosoda, 2006). As some studies have already shown (Kasper, 2004; Kurhila, 2004), however, the relevance of the NS/NNS identities within the repair practices does not always hold. The current study attempts to contribute to this line of research by introducing quantitative analysis into conversation analytic work. Previous studies in this area have typically presented detailed analyses of a few or several instances of repair found in L2 interaction data. Quantitative information, however, that is based upon careful analyses of the entire database can be a useful resource to form a general picture of the relationship between the NS/NNS identities and repair and to complement the existing findings. The present study identifies and analyzes in detail NS/NNS identity-irrelevant repairs as well as NS/NNS identity-relevant repairs for a better understanding of the socio-interactional nature of the NS/NNS identities and the interlocutors' various interactional use of repairs.

The questions that this study attempts to answer are as follows: For what purposes do participants initiate repair practices? To what extent are the NS/NNS identities relevant to the 
participants' implementation of repair work? When and through what procedures are the NS/NNS identities made relevant to the participants in repair work? What is the nature of each trouble source that leads the participants to engage in NS/NNS identity-relevant repair? The results of the study will hopefully provide valuable information on the central issues in SLA, such as when and how the NNSs' linguistic output is modified by themselves or the NSs (Kurhila, 2006). The findings of this study will also have implications for second/foreign language learning and teaching, as they will add to our knowledge of the problems that the NNS participants may experience during the course of a naturally occurring conversation.

\section{NS/NNS IDENTITIES AND REPAIR IN CA-FOR-SLA RESEARCH}

In CA-for-SLA research, which attempts to respecify SLA research in conversation analytic terms (Markee \& Kasper, 2004), NS/NNS identities are investigated from the interactioninternal participants' points of view. This is because CA-for-SLA research complies with a CA approach to social categories. In CA, social categories including NS/NNS identities are not treated as given properties. CA strongly objects to imposing any social categories on the interlocutors prior to investigating interactional practices conducted by the interlocutors. Instead, analysts are allowed to invoke descriptions with regards to the participants' social categories only when the participants manifest their orientation to such matters in and through their talk (Sacks, 1972; Schegloff, 1991, 1997; Wong \& Olsher, 2000). The CA-for-SLA researchers who investigated the association between NS/NNS identities and repair reported that interlocutors' linguistic identities were not always pertinent to the repair practices. The studies by Carroll (2004) and Kurhila (2006), for example, revealed that the NNS participants' nonnative-like utterances may show their interactional competence. Specifically, Carroll (2004), who examined self-initiated self-repair practices of Japanese novice speakers of English, found that novice L2 speakers' seemingly disfluent turns which include 'false starts' (i.e., the apparent stopping and restarting of an utterance) may not be a reflection of their nonnativeness but an interactional resource to protect the integrity of the beginnings of turn constructional units (TCU). The valid analysis of the NNSs' utterances cannot thus be provided without taking into account the interactional context in which the speech is produced. Otherwise, we may distort the nature of the $\mathrm{L} 2$ interaction and/or miss the valuable insights into the interactional purposes for which the participants use their linguistic resources.

Some CA-for-SLA studies examined the issue of when and how the participants' NS/NNS identities become relevant to the repair sequences. Kurhila (2004) and Kasper (2004) dealt with this issue by examining institutionally constructed interaction. In her analysis of Finnish conversation between L1 and L2 speakers in a range of institutional settings, Kurhila (2004) showed that the participants' orientation changed between linguistic identities and institutional identities (e.g., secretary or customer). What led the participants to orient to their 
asymmetrical linguistic identities was virtually always the display of linguistic trouble during the L2 speakers' turn. In contrast, the L1 speakers very rarely displayed their nativeness, correcting L2 speakers' language use only when the corrections were institutionally relevant and did not disturb the talk in progress. Kasper (2004) reported similar findings: although the categories of the target language expert (i.e., native) and novice (i.e., nonnative) were omnirelevant in the setting of a 'Gesprächsrunde,' a dyadic conversation-for-learning, the NS and NNS speakers of German oriented to other social categories, such as movie watchers and female acquaintances, more frequently. When the participants' linguistic identities were made relevant to the interaction, they were predominantly invoked by the NNS's repairinitiations and not by nonnative-like language use itself. The NS played their role as a language expert only in response to the NNS's repair-initiations, and the participants' orientation to their different language expertise was invariably short-lived.

With regards to ordinary conversation, as opposed to institutional talk, reference can be made to Hosoda (2006), Park (2007), and Wong (2000a, 2000b). Hosoda (2006) explored Japanese conversations between L1 speakers and L1 or L2 speakers and found that the L1 and L2 speakers did not usually orient to their co-participants' disfluencies or linguistic errors. The participants' linguistic identities became relevant to the interaction through repair practices, specifically when the L2 speaker invited the L1 speaker's repair or when mutual understanding was threatened unless the L1 speaker repaired the L2 speaker's turn. In her study of NS-NNS English conversations, Park (2007) discovered that the participants invoked their NS/NNS identities by incidentally undertaking requestor-requestee identities during a word search, a type of self-initiated repair. In addition, Park found that the participants sometimes sustained the invoked NS/NNS identities by assuming assessorassessed identities within the situated activity of evaluating self or other's linguistic performance. Park also showed that the invoked NS/NNS identities often underwent renegotiation. For instance, an NNS participant rejected the NS participants' offer of linguistic information, and another NNS participant avoided being collectively categorized as an NNS with the other NNS by strategically deploying their body and talk.

One common finding from the aforementioned studies is that participants' NS/NNS identities are not invariably relevant to the interaction. When these identities become relevant, it is mostly through the NNS participants' repair-initiation on their language problems in producing, hearing, and/or understanding the talk. The NS participants reveal their nativeness by implementing other-repair or correction of the NNS participants' linguistically problematic utterances. They do this when it is requested by the NNS participants or when it is essential to advancing their conversation or achieving their interactional goal. In spite of the differences in the languages and interactional contexts explored, these studies reveal that the NS/NNS identities are social and dynamic entities and that the NNS participants are 'social beings in real world situations' (Park, 2007, p. 340). 
Earlier studies, however, have not exhaustively examined all aspects of the relationship between the NS/NNS identities and repair practices. In particular, quantitative data, which are not available in previous research, may complement and/or corroborate the aforementioned conversation-analytic findings. By taking existing research as a point of departure and expanding it, the present study thus seeks to paint a broader picture of the relationship between the NS/NNS identities and repair practices through quantification that builds upon conversation analyses of individual repair instances. Based on the findings, the study also attempts to shed more light on the socio-interactional and dynamic nature of the NS/NNS identities and further support the view which regards the NNS participants as social beings rather than reduced learner personas.

\section{THE DATA}

The data analysed in this study consist of five sets of NS-NNS conversations, which are about 4 hours and 45 minutes long in total. Three American NSs and eight Korean NNSs were involved in naturally occurring casual conversations (see Table 1 below).

Table 1. Data Description

\begin{tabular}{llll}
\hline $\begin{array}{l}\text { Data } \\
\text { Set }\end{array}$ & Participants & Places & Length (min) \\
\hline 1 & Amy, Dasom & Photocopy Room at Workplace & 20 \\
2 & Bob, Dasom, Eunju, Mijin & Restaurant 1 & 30 \\
3 & Bob, Garam & Meeting Room 1 in Church & 43 \\
4 & Bob, Eunju, Hansu, Junsu & Meeting Room 2 in Church & 90 \\
5 & Chris, Sumi, Jisu & Restaurant 2 & 102 \\
\hline
\end{tabular}

All of the participants were young adults in their twenties except Bob, who was in late forties, and most of them were close friends or acquaintances. Data were collected during break times at work, during dinners at restaurants, and at a church in Korea. Since the NS participants' proficiency in Korean was at the very beginning level and the NNS participants all knew how to speak English, the NS and NNS participants adopted English as their lingua franca in carrying out conversations. The NNS participants all learned English as a foreign language through formal instruction and their general English proficiency as measured by official English tests (such as the Test of English Proficiency developed by Seoul National University and the Test of English for International Communication) was at the intermediate or advanced level. 
The conversations were audio-recorded by one of the researchers or one of the participants upon request. Despite the limited access to some semiotic resources such as gaze or body movements to which the participants might be oriented, audio-recording was used over video-recording for practical reasons. Compared to video-cameras, audio-recorders much less disturb or distract the participants and other people in and around the research sites. Moreover, some of the research sites (e.g., public restaurants and a photocopy room of a private company) are not normally allowed to video-tape in. All of the participants consented to the recording of their conversations and the use of the recording for research purposes. Pseudonyms were used in the transcripts to protect the privacy of the participants. The data were transcribed following the transcription conventions developed and elaborated by Jefferson (Ochs, Schegloff \& Thompson, 1996; see the Appendix for the transcription conventions).

\section{METHODOLOGY}

\section{METHODOLOGICAL FRAMEWORK}

The present study is conducted within the theoretical and methodological framework of conversation analysis (CA). The value of CA as a useful tool for the study of learner language in interaction has been attested to through numerous studies (e.g., Brown, 2003; Carroll, 2000, 2004; Firth, 1996; Gardner \& Wagner, 2004; He, 2004; Hosoda, 2000, 2006; Kasper, 2004; Kurhila, 2004, 2006; Markee, 2004; Mori, 2004; Park, 2007; Richards \& Seedhouse, 2005; Seedhouse, 2004; Wong 2000a, 2000b, 2005). Using CA as the framework for the analysis and thereby investigating the relationship between the NS/NNS identities and repair from the participants' point of view, this study seeks to provide a more adequate and detailed account of the nature of NS/NNS identities in NS-NNS interaction. One departure from the traditional CA studies, however, is that the current study implemented a frequency analysis to assess the relationship between NS/NNS identities and repair from a quantitative perspective. Although most studies of CA-for-SLA do not investigate this relationship quantitatively, quantitative information can contribute to attaining a general picture of repair practices and their relationship with NS/NNS identities. Indeed, Heritage (1999) acknowledges the usefulness of, and in some cases the need for, quantification in CA studies, especially of 'applied kind.' Taking into account Schegloff's (1993, 2009) critique of quantifying social interaction where he emphasizes the irreplaceability of single case analysis with quantitative analysis, the frequency analysis of the current study builds on detailed caseby-case analysis of repair instances being investigated from the participants' perspective(s).

\section{ANALYTICAL PROCEDURES}

To investigate the relationship between the NS/NNS identities and repair practices, all the repair instances that occurred between NS and NNS participants were first identified in the database. They were subsequently classified into the four categories of repair (Schegloff et 
al., 1977), i.e., self-initiated self-repair (SISR), self-initiated other-repair (SIOR), otherinitiated self-repair (OISR), and other-initiated other-repair (OIOR), depending on who initiates and completes repair. SISR is both initiated and completed by the speaker of the trouble source, and OIOR, by someone other than the speaker. SIOR is initiated by the speaker of the trouble source and completed by some other participant in talk, and in the case of OISR, vice versa. Examples of each repair type are provided later.

Among the four types of repair, instances of SISR were excluded from the repair collection for the present study due to the complexity of analysing the relevance of NS/NNS identities to them. The vast majority of SISR instances were same-turn repairs, meaning that the speaker of the trouble source initiates and completes repair within the current turn. In such cases, other participants do not normally make any remarks which displays their understanding of the nature of the repair during or after the repair work. Absence of this information, which is critical in establishing the relevance of NS/NNS identities to a given repair from an emic perspective, led the researchers to leave SISR out in this study. As for the other three categories of repair (i.e., SIOR, OISR, and OIOR), the number was counted of repair instances belonging to each category.

After the above procedure, each repair sequence was analysed in great detail in order to find out for what interactional purposes the participants engage in repair practices. Each repair instance was also closely examined with special focus on whether NS/NNS identity was relevant to the repair or not. When an ambiguous instance arose, it was neither dismissed as an abnormal case nor forced into either of the two categories; instead, it was carefully re-examined to account for its very ambiguity from the participants' point of view (Examples of NS/NNS identity(ir)relevant repairs and ambiguous cases are provided in the RESULTS AND DISCUSSION section). Within each of the three repair categories, the numbers of NS/NNS identity-relevant and NS/NNS identity-irrelevant repair instances were then counted, and the ratio of the former to the latter was also calculated. Yet, the ambiguous cases, of which there were three, were not subjected to quantitative analysis given their ambiguity.

As a method of examining when and how the participants invoke their own or interlocutors' NS/NNS identities through repair practices, the NS/NNS identity-relevant repair instances were further divided into two groups based on who initiated the repair, that is, whether they were NS-initiated or NNS-initiated repair instances. The same procedure was also applied to the NS/NNS identity-irrelevant repairs for the purpose of comparison. Additionally, the interactional environments in which the NS participants initially invoked the NS/NNS identities were explored in detail, given the reported rarity of NS's initial invocation of NS/NNS identities in the literature (e.g., Hosoda, 2006; Park, 2007; Kasper, 2004; Kurhila, 2004; Wong, 2000a, 2000b). 
Lastly, with regards to the NS/NNS identity-relevant repair, the nature of each trouble source was examined, focusing on how the NS/NNS participants constitute the causes of their own or other's troubles in speaking, hearing, and/or understanding talk through the composition of their turn. Various types of troubles were grouped into the two categories of production problems and reception problems based on whether the cause of a trouble was attributed, respectively, to NNS's speaking or to NNSs' hearing and/or understanding of NS's talk.

\section{RELIABILITY OF CLASSIFICATION}

Following the analytical procedures described above, the two researchers individually identified and classified all repair instances in one of the data sets (the data set 3 ) to ensure inter-rater reliability of repair classification. Inter-rater reliability was measured using Cohen's Kappa statistic with 95\% confidence interval. The Cohen's Kappa value was 0.889, which indicates that the strength of agreement is very good. One of the researchers then performed the identification and classification of the rest of the repair instances in the database. When problematic cases arose, the two researchers discussed them together and reached an agreement.

\section{RESULTS AND DISCUSSION}

This section first illustrates conversation analyses that have been conducted on the entire repair collection, which set the foundation for the subsequent quantitative analysis. The first subsection presents detailed analyses of repair sequences, examining for what interactional purposes the participants engage in repair practices, and when and how their NS/NNS or some other identities of are made relevant to the repair work. The second subsection provides examples of NS/NNS identity-relevant repairs which deal with the NNS participants' production and perceptive problems. The results of quantitative analysis follow in the last subsection.

\section{RELEVANCE OF NS/NNS IDENTITY TO REPAIR PRACTICES}

\section{NS/NNS Identity-Irrelevant Repair}

The three repair sequences to be examined here exemplify the cases in which the participants do not treat the NS/NNS identities as relevant to the interaction at the moment and use repair sequences for purposes other than clearing language problems. In Excerpt 1, which is an example of NS/NNS identity-irrelevant SIOR, the participants are having dinner at a restaurant, sharing a chicken dish. Noticing that the other participants have stopped eating the dish, in lines 1, 2, 6, and 7 the NS participant Bob asks whether he can have the rest of the chicken and whether they are saving it for another person who is supposed to join the dinner. 
Excerpt 1 [Restaurant 1]

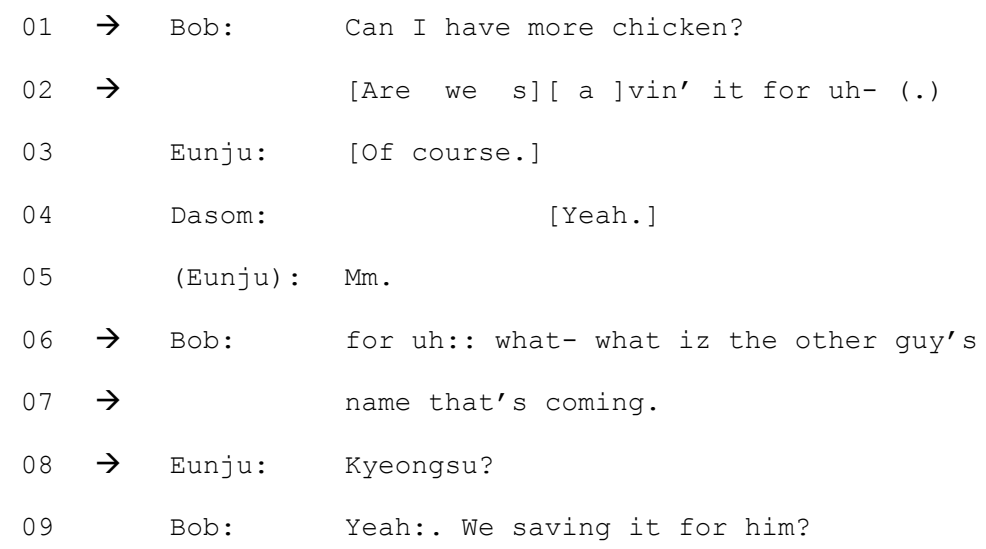

Bob, however, displays his trouble in remembering the person's name. When he reaches the part of his utterance where the person's name is due, he initiates a repair on his own talk by putting a place holder $u h$ in place of the name, which is soon followed by a cut-off and a micropause (line 2). In line 6 , he restarts his halted turn but again fails to provide the name as demonstrated by the use of elongated $u h::$ in place of the name due. Afterwards, Bob explicitly invites other participants' help by issuing the question what- what iz the other guy's name that's coming (lines 6 and 7). By doing so, Bob presents himself as a person who has trouble remembering the guy's name whereas positioning the other participants as those who can provide it. In response to it, in line 8 the NNS participant Eunju proffers the searched name Kyeongsu with a rising intonation. In the subsequent line, Bob accepts the repair solution provided by Eunju with Yeah: and returns to his original question, this time re-designing some of the elements of his previous question. As the analysis has demonstrated, this SIOR instance between Bob and Eunju is not relevant to their NS/NNS identities. Rather through the repair practice, Bob is constituted as a person who does not remember his acquaintance's name whereas Eunju as a person who knows the person by name, which arguably suggests that Eunju's social relationship to Kyeongsu, compared to that of Bob, is much closer. ${ }^{2}$

Excerpt 2 illustrates an example of NS/NNS identity-irrelevant OISR. In this example, the NNS participant Hansu is explaining his job duties at an advertisement company. Hansu states that he, as a project manager, is now engaged in a new marketing project concerning viral marketing techniques. 
Excerpt 2 [Meeting Room 2]

\begin{tabular}{|c|c|c|c|}
\hline 01 & & Hansu: & Viral maketing(.) do you heard? \\
\hline 02 & & & eu do you: (0.3) have you heard? \\
\hline 03 & & & $(1.8)$ \\
\hline 04 & & Hansu: & [ Buzz ] maketing \\
\hline 05 & & Bob: & {$[$ (About) $]$} \\
\hline 06 & $\rightarrow$ & Bob: & Buzz markeding? \\
\hline 07 & $\rightarrow$ & Hansu: & Yeah. \\
\hline 08 & & & $(1.2)$ \\
\hline 09 & $\rightarrow$ & Bob: & No. \\
\hline
\end{tabular}

In lines 1 and 2, introducing the technical term Viral maketing (viral marketing), Hansu asks Bob who is an NS if he has ever heard of the term. ${ }^{3}$ Hansu's question makes either a yes or a no answer from Bob relevant next. With Bob's answer not forthcoming (see the 1.8 second gap in line 3), which often signals an impending dispreferred response (Schegloff, 2007), ${ }^{4}$ Hansu begins to rework his question replacing the key technical term used in it (i.e., Viral marketing) with a more vernacular type (Buzz marketing). From the entire sequence of this interaction, which is not provided here due to the space restrictions, Hansu is seen to use the term Buzz maketing (buzz marketing) as a stepping stone for explaining the meaning of Viral maketing. Hansu's question itself reveals himself as someone who possesses special knowledge of the technical term viral or buzz marketing and Bob as someone who may or may not have knowledge of this concept.

As it happens, Hansu's turn in line 4 comes in overlap with Bob's turn-initial element, and in line 6, Bob initiates repair on Hansu's utterance by repeating it with a rising intonation. Although Bob's pronunciation is different from his, Hansu does not take this repair-initiation as an indication of a linguistic error in his talk. Hansu understands Bob's turn as a request for confirmation, so he confirms Bob's hearing with Yeah in line 7. Bob's response to Hansu's confirmation shows that Hansu was correct in so understanding. Instead of correcting Hansu's pronunciation error, in line 9 Bob gives the negative answer of No to the question issued in line 4 (as foreshadowed by the 1.2 second silence in line 8) and manifests his ignorance of the marketing term. The unfolding interactional details in this repair work thus show that Bob's repair-initiation does not make the participants' NS/NNS identities relevant. Rather, Bob's repair-initiation demonstrates the uneven distribution of marketing knowledge 
between Bob and Hansu, and thereby makes Bob's layperson and Hansu's marketing expert identities pertinent to the repair practice.

Excerpt 3 shows an example of NS-NNS identity irrelevant OIOR. The excerpt begins with the NS participant Bob estimating how long it will take for him to finish the Korean language textbook called hankwuke $i$ (Korean II) if he studies it at his current pace.

Excerpt 3 [Meeting Room 1]

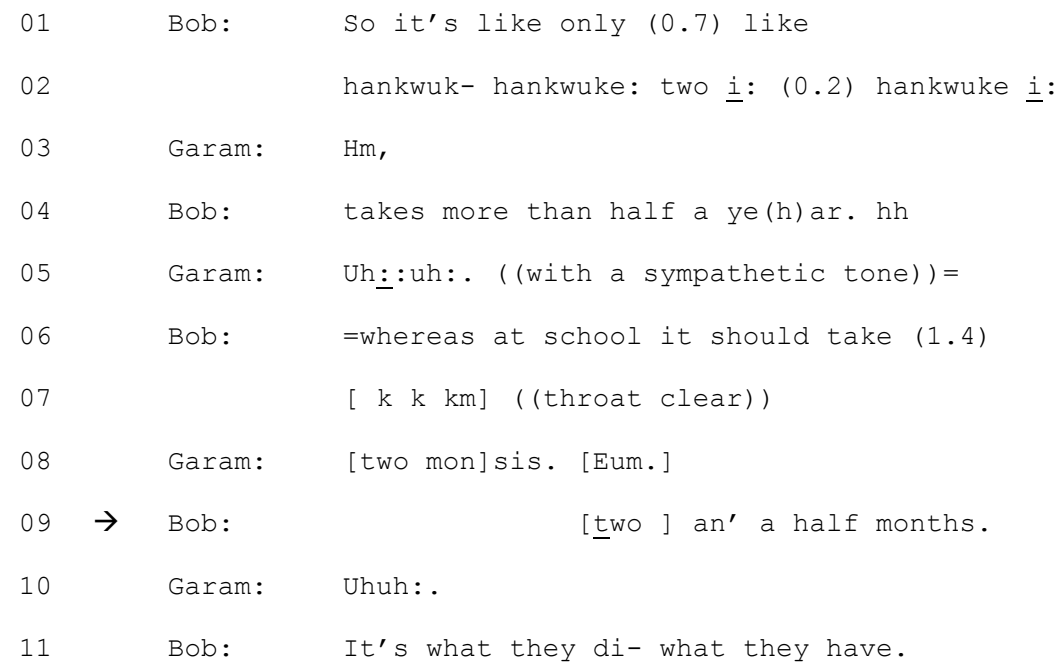

As a means to show how slowly his study of the Korean textbook progresses, in line 6 Bob attempts to compare his pace with that of a Korean language school which he used to attend. In doing so, however, he displays trouble in smoothly progressing his utterance as demonstrated by a 1.4 second pause. Taking this opportunity, in line 8 Garam completes Bob's talk-inprogress by assertively providing the next item due, two monsis (two months), that is, the timeline of the language school's covering the same textbook. ${ }^{5}$ She also adds an acknowledgement token Eum, which accepts not only Bob's utterance in line 6 but also her own rendition of what Bob was going to say in line 8. What follows next is, however, Bob's OIOR on Garam's contribution. In line 9 right after Garam's production of two monsis (two months), Bob makes a factual correction on Garam's contribution by saying two an' a half months. Through the repair practice, Bob thus claims his epistemic authority over the language school's timeline. In that sense, Bob's repair in line 9 is not relevant with Garam's or his NS/NNS identity. ${ }^{6}$ Rather, it differentiates Bob from Garam in terms of knowledge about the language school's instruction schedule for hankwuke $i$ (Korean II) learners. In line 10, Garam accepts Bob's correction with the acknowledgment token Uhuh:; thereby acknowledging Bob's 
epistemic authority in this matter. In line 11, Bob adds that the period of two and a half months is what the language school has on their schedule. By doing so, Bob further claims his authority on the provided length of time in that he clearly indicates that the information he provided is not based on his personal opinion but on the objective and reliable source.

As can be seen in Excerpt 1 through 3, the NS and NNS participants in this study were not always oriented to their linguistic identities. A range of other social identities or relationships came into play during the repair work. Furthermore, the NS and NNS participants sometimes passed opportunities to invoke their NS/NNS identities by ignoring the NNS participants' linguistic errors. By doing so, at the surface level, the NS and NNS participants appear to hold the NNS participants who produce turns containing language problems as 'competent users' of English or, at least, leave the issue of the NNS participants' linguistic incompetence unuttered (Wong, 2005, p. 164).

\section{NS/NNS Identity-Relevant Repair}

In repair practices, the participants' NS/NNS identities are made relevant when the NS and NNS participants orient to NNS participants' insufficient linguistic abilities in speaking, hearing, and understanding the talk. Three excerpts presented and analysed in this subsection are examples of these cases. In Excerpt 4, which exemplifies NS/NNS identity-relevant SIOR, the NNS participant Dasom attempts to explain why she wants to see cherry blossoms at that particular weekend by pointing out that the weekend is the peak time for the flower viewing. In providing the explanation, she displays a trouble in speaking.

Excerpt 4 [Photocopy Room]

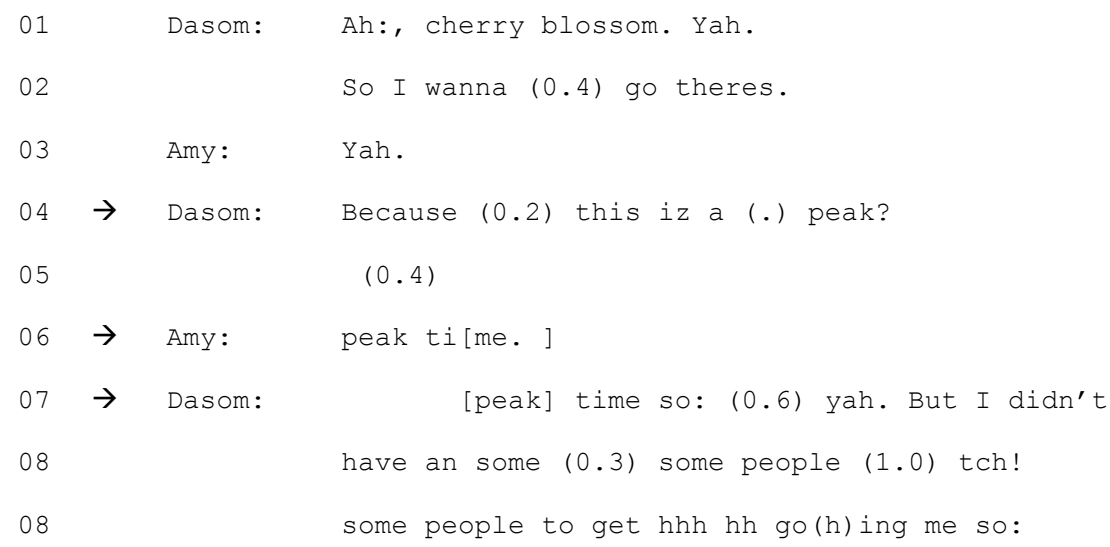


Specifically, in line 4, right before the production of peak (as well as following Because), Dasom briefly holds her turn-in-progress and it yields a pause, which signals a potential trouble in her completing the turn. When Dasom produces the next item due peak, Dasom utters it with a rising intonation rather than a falling intonation. The rising intonation not only indicates Dasom's uncertainty regarding her word choice peak but also invites Amy to help her clear up her language problem, thereby making the participants' NS/NNS identities relevant to the interaction.

In line 6, Amy indeed joins Dasom's self-initiated repair by providing a solution to the language problem. Amy provides Dasom with the English expression peak time in an assertive manner with a falling intonation contour. Amy's display of assurance of her repair work shows that Amy issued repair from a knowledgeable position (Drew, 1991) and that she is oriented to her NS identity. In line 7, at the earliest possible point where Dasom was able to recognize Amy's repair solution, Dasom continues her utterance by incorporating the expression peak time as an element of her turn without any hesitation. Dasom's straightforward acceptance of the repair solution shows her orientation to Amy's identity as a competent English speaker. After clearing up her trouble in speaking, Dasom trails off her utterance with the use of so: and exits the TCU with yah (Park, 2004). Dasom moves on to add that her plan may be unfeasible because she cannot find people to go with her.

Excerpt 5 illustrates how the NNS participant Garam and the NS participant Bob orient to their linguistic asymmetry when they are involved in dealing with Garam's mishearing of a word through OISR. In this part of the interaction, Bob introduces his trouble in remembering Korean words using the example of his experience at a park. Bob needed to identify the owners of the coats on the slide so that his daughter could go up the slide, but he forgot how to express it in Korean. In line 1, Bob explains the beginning of this situation.

\section{Excerpt 5 [Meeting Room 1]}

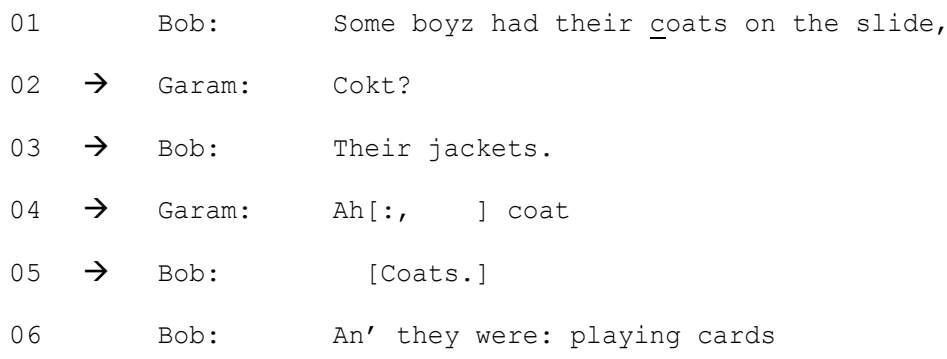

In line 2, Garam starts other-initiation of repair by repeating a part of Bob's utterance with a rising intonation, which is a typical repair-initiation technique to signal a hearing problem (Svennevig, 2008). In doing so, however, she fails to produce the word coats with the correct 
pronunciation, pronouncing it as Cokt. Bob's subsequent repair work displays that he took Garam's repair-initiation as a demonstration of her insufficient linguistic competence in perceiving the common English word. In other words, Bob treats Garam's repair-initiation as a manifestation of her nonnativeness. Consider line 3 where Bob joins the repair work. Using the word jackets, a synonym of coats, he provides the meaning of the target word. In doing so, Bob produces the word jackets in a confident manner with a downward intonation, which displays his linguistic authority. Bob's repair work is taken by Garam with the 'change-ofstate' token (Heritage, 1984) in Korean, Ah (Park, 2008). Then, she displays her revised perception of the sounds of coats by producing the word coat. Right after she starts to produce the token $A h$ : in line 5 Bob supplies the correct pronunciation of coats by repeating the trouble source, again in an assertive manner with a falling intonation. This demonstrates that Bob takes Garam's trouble to be phonological (and not the semantic) aspect of the word coats, ${ }^{7}$ and Garam's turn in line 4 shows that Bob was correct in so understanding. Garam's coat in line 4 was not exact repetition of Bob's pronunciation of coats in lines 1 and 5 in that she produced the word in its base form instead of the plural form. Yet, as the pronunciation was correct, Bob passes an opportunity to initiate and/or do repair on Garam's grammatical error. In line 6 , Bob returns to the storytelling sequence by continuing his description of the situation with the conjunction $A n$ ' (and), which links the turn in line 6 to the turn in line 1 .

Excerpt 6, which is taken from the same occasion as Excerpt 4, illustrates how the NS participant Amy makes the participants' NS/NNS identities relevant to the interaction by implementing OIOR on the NNS participant Dasom's use of the word flower. In lines 1 through 3, sharing her plans for the weekend with Amy, Dasom mentions that she wants to go on a picnic because the flowers are in full bloom.

Excerpt 6 [Photocopy Room]

$$
\text { Dasom: }
$$$$
\text { An' : : an' }
$$$$
\text { then I wanna }
$$$$
(0.5) \text { go on }(0.2)
$$

Yet, Dasom's use of the word flower becomes problematic in line 4, where the NS participant Amy implements OIOR on the word flower. In place of the word flower, which encompasses all types of flowers, Amy provides the name of the flower, cherry blossoms, thereby specifying the flower type. By doing so, Amy projects herself as an expert of English, who has the specific word for what Dasom refers to as the general flower. It is also here that she portrays Dasom as a person who may not know the word cherry blossoms. 
Additionally, consider that Amy pronounces the word cherry blossoms with a relatively louder than usual voice, which could be understood as a prosodic aid for Dasom to easily recognize Amy's production of the word cherry blossoms. When Amy finishes the word cherry blossoms, she employs a falling intonation, which displays her epistemic authority in correcting Dasom's word choice. In this sense, Amy's repair differentiates her and Dasom's levels of English proficiency and makes it relevant to their interaction.

Through Excerpts 4-6, it has been demonstrated that NS/NNS identities may be made relevant by the NS and NNS participants' orientation to the NNS participants' language problems in speaking, hearing, or understanding the talk with the implementation of repair.

\section{Ambiguous Cases}

In preceding subsections, examples of NS/NNS identity-(ir)relevant SIOR, OISR, and OIOR have been discussed. Yet, not all the repair instances are clearly categorisable into either NS/NNS identity-relevant or NS/NS identity-irrelevant repairs. Excerpt 7 below illustrates an example of ambiguous cases. Where the excerpt begins, the NNS participant Junsu opens the door and tries to enter the room where an English Bible study group is meeting in order to look for something. Upon finding the unexpected meeting there, he apologizes for his sudden interruption to the meeting (line 1). This, however, is mistaken by the NS participant Bob as an apology for arriving late, who thus urges Junsu to come in and join the meeting (line 2).

Excerpt 7 [Meeting Room 2]

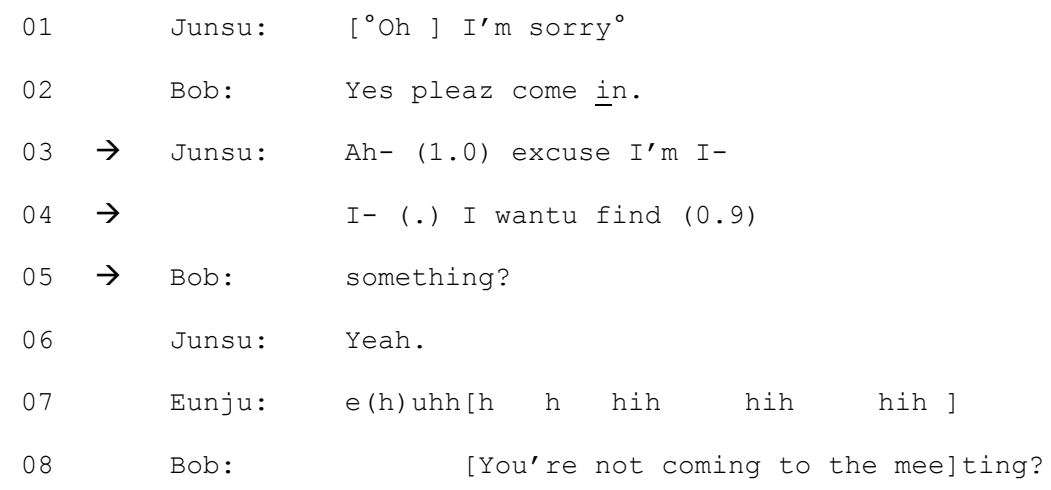

In response to Bob's invitation to the meeting, in lines 3 and 4 Junsu rejects it by providing his original purpose of entering the room. In doing so, he displays many troubles in completing his turn: He is engaged in several attempts to do SISR (e.g., I'm I- I- (.) I wantu); he also fails to provide the last element of his talk, yielding a 0.9 second pause, which signals self-initiation of repair. In line 5 , Bob provides a candidate next item due something for 
Junsu, who accepts it with Yeah. The SIOR between Junsu and Bob in lines 3 through 5 could be understood as NS/NNS identity-relevant repair given that Junsu's demonstrated disfluencies in lines 3 and 4 may be seen to have led Junsu to orient to his linguistic incompetence, and Bob to take a linguistic expert identity and provide the word being searched. An alternative analysis, however, may also be applicable to this repair sequence. Junsu's displayed disfluencies in lines 3 and 4 could be understood as an interactional resource to further delay the dispreferred response and/or the completion of it. Additionally, employing the 0.9 second pause and letting Bob provide the last element of his talk, Junsu might be strategically placing himself in a position where he does not have to complete the dispreferred response but simply confirms it, as he did in line 6. Instead of dichotomizing Junsu's demonstrated disfluences into either language-related or dispreferred responserelated ones, this repair sequence could also be understood as an example of strategic use of linguistic disfluences as a means of dealing with an interactional problem of how to deliver a dispreferred response. In this sense, Junsu and Bob's repair work cannot be easily categorized into either NS/NNS identity-relevant or NS/NNS identity-irrelevant repair. Ambiguous cases such as Excerpt 7 thus clearly show the importance of carrying out conversation analyses on each repair instance, which enables researchers to take into account interactional contingencies of a particular interactional moment.

\section{NNS PARTICIPANTS' PRODUCTION AND PERCEPTION PROBLEMS}

This subsection demonstrates the analyses of the nature of trouble source in the case of NS/NNS identity-relevant repairs. ${ }^{8}$ The two main categories of the NNS participants' production problems and perceptions problems have emerged from the analysis of their language-related troubles which led the NS and NNS participants to engage in repairs.

Repairs in Excerpts 8, 9, and 10 are all categorized as instances of the NNS participants' production problems since what triggers the participants' repair work was the NNS participants' problematic production of English, whether it is an uncertain production of vocabulary, a problem with pronunciation of a word, or a problem with vocabulary choice. Specifically, in Excerpt 8, which is part of Excerpt 4, the NNS participant Dasom initiates a SIOR sequence by checking her use of the word peak with the NS participant Amy, displaying her uncertainty with the use of the word peak (line 1). By doing so, she problematises her production of the word peak and invites Amy to join the repair work.

Excerpt 8 [Photocopy Room]

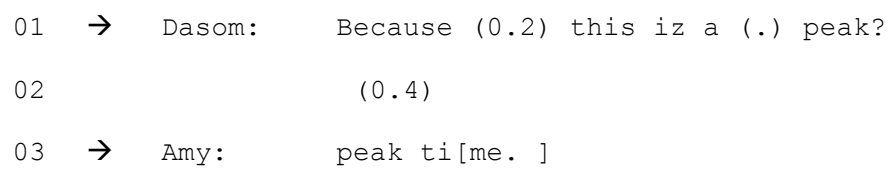


In Excerpt 9, the NS participant Bob initiates an OISR sequence in line 3 so that he can resolve his hearing problem. In response to Bob's repair-initiation, the NNS participant Hansu changes his pronunciation of the word blog a few times, thereby attributing Bob's trouble in perceiving the word to his own pronunciation problem.

Excerpt 9 [Meeting Room 2]

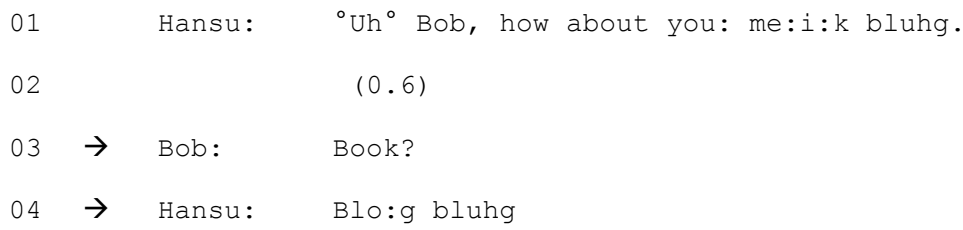

In Excerpt 10, which is part of Excerpt 6, the NS participant Amy implements OIOR on the NNS participant Dasom's use of the word flower by specifying the name of the flower as

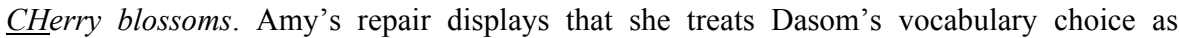
problematic (line 4).

Excerpt 10 [Photocopy Room]

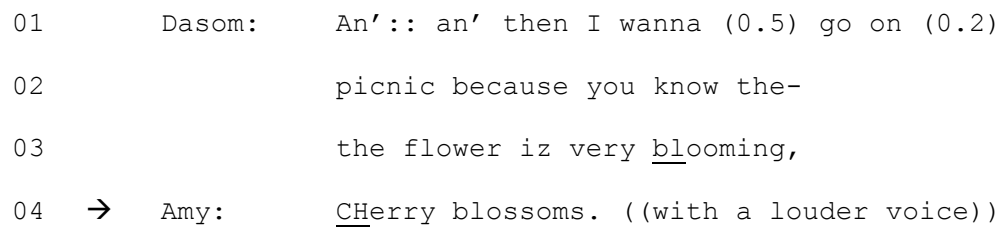

Now, let us turn to examples of repair sequences triggered by the NNS participants' problems in perceiving the NS participants' talk. Excerpt 11, which is part of Excerpt 5, illustrates a case where a repair sequence is launched to address the NNS participant's problem in perceiving the spoken form of vocabulary.

Excerpt 11 [Meeting Room 1]

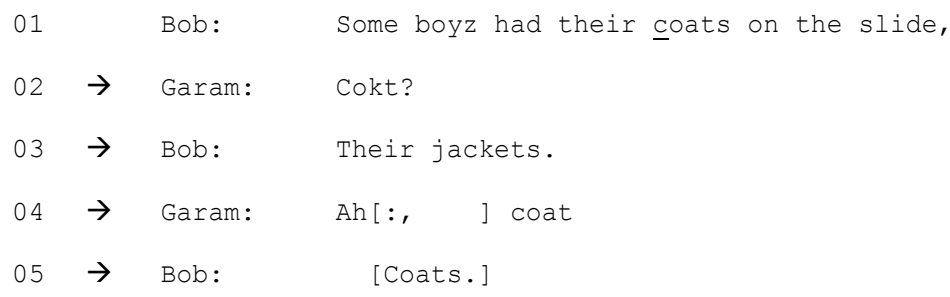


In line 2, the NNS participant Garam initiates a repair on the NNS participant Bob's prior talk by producing her candidate hearing of the word coats with a rising intonation. In lines 3 and 5, the NS participant Bob provides a repair solution by saying Their jackets and Coats, which displays his understanding of Garam's repair initiation as an indication of her problem in perceiving the spoken form of the word coats. Although it is unclear whether Garam was able to utilize Bob's repair in line 5 due to its overlap with her production of $A h$ :, Bob's repair work comes to fruition given that in line 4 Garam displays her successful perception of the sounds of coats by saying coat.

Excerpt 12 shows a repair sequence which deals with an NNS participant's problem in perceiving the meaning of a verb phrase. Here, the NS participant Bob is explaining how Americans fight against childhood obesity by banning soda in schools.

Excerpt 12 [Meeting Room 2]

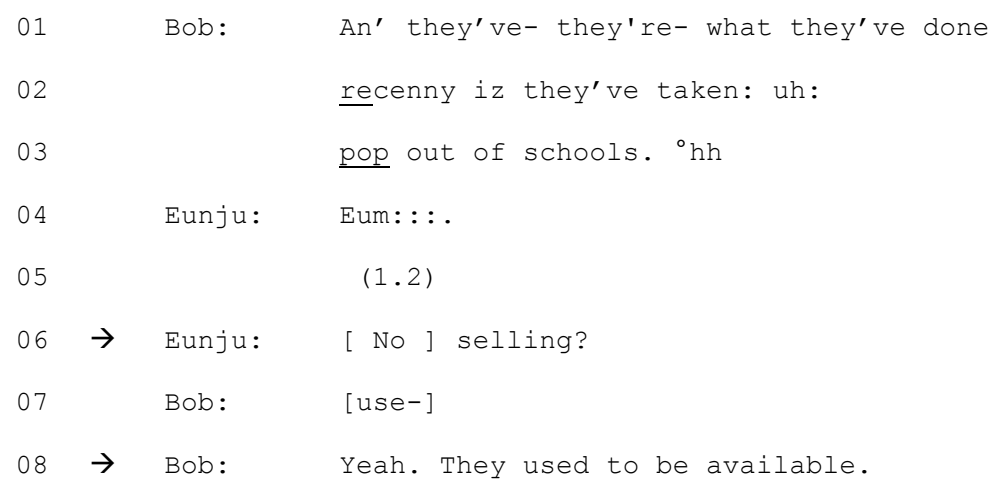

In line 4, the NNS participant Eunju initially receives Bob's explanation with Eum::., thereby claiming her understanding of it. However, after a 1.2 second silence, she initiates an OISR sequence by proffering her candidate understanding of some elements of his talk for Bob's (dis)confirmation on it. ${ }^{9}$ The composition of the proffered candidate understanding (i.e., No selling?) displays that Eunju has trouble in perceiving the meaning of the verb phrase take something out of somewhere. In line 8, Bob confirms her candidate understanding with Yeah and resumes his talk which has stopped in line 6 due to Eunju's repair-initiation.

\section{RESULTS OF QUANTITATIVE ANALYSIS}

Based upon the conversation analysis of whether the NS/NNS identity of the participants was relevant or not in each repair sequence identified, three types of frequency analysis were carried out, of which the results are reported below. First, the ratio of the NS/NNS identityrelevant repairs to the NS/NNS identity-irrelevant repairs is calculated of the three repair 
categories (i.e., SIOR, OISR, and OIOR). Second, the proportion of the NNS-initiated repairs to the NS-initiated repairs is gauged with respect to the relevance of the NS/NNS identities. The last finding of quantitative analyses concerns the nature of NNS participants' language problems which trigger repair sequences in the case of the NS/NNS identity-relevant repairs.

Let us first examine the results regarding the ratio between the NS/NNS identity-relevant and -irrelevant repairs.

Table 2. SIOR, OISR, OIOR and NS/NNS Identities

\begin{tabular}{lllll}
\hline Repair Type & \multicolumn{1}{c}{ NS/NNS Identity- } \\
Relevant & \multicolumn{1}{c}{$\begin{array}{c}\text { NS/NNS Identity- } \\
\text { Irrelevant }\end{array}$} \\
\hline SIOR & $25(37.9 \%)$ & $41(62.1 \%)$ & $66(100 \%)$ & $(22.1 \%)$ \\
OISR & $50(27.8 \%)$ & $130(72.2 \%)$ & $180(100 \%)$ & $(60.4 \%)$ \\
OIOR & $31(59.6 \%)$ & $21(40.4 \%)$ & $52(100 \%)$ & $(17.5 \%)$ \\
Total & $106(35.6 \%)$ & $192(64.4 \%)$ & Grand Total: $298(100 \%)$ \\
\hline
\end{tabular}

As seen from Table 2, among a total of 298 repairs, 106 (35.6\%) repairs were related, and the remaining $192(64.4 \%)$ repairs were irrelevant, to NS/NNS identities. In other words, considering the repair instances in the aggregate, the number of NS/NNS identity-irrelevant repair instances was greater than that of NS/NNS identity-relevant ones. This finding challenges the presumed relevance of NS/NNS identities to repair practices in NS-NNS interaction, thereby providing empirical evidence for approaching NS/NNS identities from an emic perspective (Firth \& Wagner, 1997). The overall repair trend shows that the NS and NNS participants frequently initiated repair for reasons other than solving language problems such as helping others to recall names, dealing with non-understanding of technical terms, or making a factual correction on given information. In particular, for OISR, which constitutes the majority (60.4\%) of the total repair instances, the fraction of NS/NNS identity-irrelevant repair instances was $72.2 \%$ of the total OISRs. Similarly, within SIOR, the number of NS/NNS identityirrelevant repair instances was greater (62.1\%) than that of NS/NNS identity-relevant ones (37.9\%). Within OIOR, however, the number of NS/NNS identity-relevant repairs was higher $(59.6 \%)$ than that of NS/NNS identity-irrelevant ones (40.4\%), showing roughly a ratio of six to four for the former to the latter. This reveals that in the majority of cases when the NS and NNS participants were engaged in OIOR, the participants were dealing with their language problems through repair operations. It is important to note, however, that even within OIOR, there was a fair number of NS/NNS identity-irrelevant repairs.

Next, all of the SIOR, OISR, and OIOR repairs were re-examined with respect to who initiated the repair sequence (see Table 3). 


\begin{tabular}{llllll}
\hline & \multicolumn{2}{c}{ NS/NNS Identity-Relevant } & \multicolumn{2}{c}{ NS/NNS Identity-Irrelevant } & \multirow{2}{*}{ Total } \\
\cline { 2 - 4 } & \multicolumn{2}{c}{ NS-Initiated } & NNS-Initiated & NS-Initiated & NNS-Initiated \\
\hline SIOR & $0(0 \%)$ & $25(100 \%)$ & $31(75.6 \%)$ & $10(24.4 \%)$ & $66(22.1 \%)$ \\
OISR & $9(18 \%)$ & $41(82 \%)$ & $52(40 \%)$ & $78(60 \%)$ & $180(60.4)$ \\
OIOR & $28(90.3 \%)$ & $3(9.7 \%)$ & $13(61.9 \%)$ & $8(38.1 \%)$ & $52(17.5 \%)$ \\
Total & $37(34.9 \%)$ & $69(65.1 \%)$ & $96(50 \%)$ & $96(50 \%)$ & Grand Total: \\
\hline
\end{tabular}

Out of the 298 repair instances, NNS-initiated repair accounted for 165 (55.4\%) repairs and NS-initiated repair, $133(44.6 \%)$. The data reveal that the NNS participants actively took the initiative to solve interactional problems and were not passive but active communicators. In particular, regarding NS/NNS identity-relevant repairs, the NNS participants initiated 69 $(65.1 \%)$ repairs in an attempt to solve their language problems. On the other hand, the NS participants initiated $37(34.9 \%)$ repair sequences in order to solve troubles caused by the NNS participants' language problems. The results thus show that in the majority of the NS/NNS identity-relevant repairs, the NNS participants first disclosed their language problems through repair-initiation. Especially, within NS/NNS identity-relevant OISR, the NS participants initiated only nine (18\%) repairs out of 50 , whereas within NS/NNS identityirrelevant OISR, they initiated $52(40 \%)$ repairs out of 130 . Yet, the results of the present study also reveal that there exist quite a number of NS/NNS identity-relevant repairs initiated by the NS participants (34.9\%), which seemingly goes against the reported rarity of NSinitiated NS/NNS-identity relevant repairs in both everyday and (quasi-)institutional talk (Hosoda, 2006; Kasper, 2004; Kurhila, 2004). The apparent discrepancy between the current and previous studies makes it worthwhile to delve into the interactional environments in which the NS participants initially invoked the NS/NNS identities. To begin with, we will examine the instances of OISR, and then move onto the OIOR.

Among the nine instances of NS/NNS-identity relevant OISR initiated by the NS participants, eight occurred when the NS participants were not able to produce a sequentially appropriate next turn unless they cleared up their troubles in recognizing and/or understanding the NNS participants' talk. ${ }^{10}$ Only one repair occurred as a way for an NS participant to locate a trouble source in an NNS's talk so that the NNS participant could selfrepair the trouble source although the NS participant had no trouble understanding the talk. ${ }^{11}$

In case of NS/NNS identity-relevant OIOR, out of the 31 repair instances, NS-initiated repair accounted for $28(90.3 \%)$ repairs, and NNS-initiated repair, only for three $(9.7 \%) .{ }^{12}$ 
Specifically, in the majority of cases $(n=17,60.7 \%)$, the NS participants implemented OIOR on the trouble sources on which the NNS participants previously initiated repair. For instance, the NS participants initiated OIOR when the NNS participants first displayed difficulties in composing their turn by initiating SISR or SIOR, or in hearing and/or understanding the prior talk by initiating OISR. ${ }^{13}$ Three (10.7\%) OIORs initiated by the NS participants occurred when there were some sorts of (potential) understanding problems. The NS participants implemented OIOR on the NNS participants' talk when the NNS participants displayed their non- or misunderstanding of the NS participants' talk, or when the NNS participants' talk was potentially non-understandable to its addressee. ${ }^{14}$ Eight $(28.6 \%)$ repairs did not take place in any of these environments. Yet, what is interesting is that almost all of these repairs (i.e., seven) were modulated in form. For instance, the NS participants frequently employed a rising intonation at the end of their OIOR in order to downgrade the certainty of their repair work. ${ }^{15}$ Even in the case of the one exceptional repair, the NS participant initially modulated his OIOR by employing a rising intonation although he later replaced it with a falling intonation. ${ }^{16}$

The close examination on the NS/NNS identity-relevant OISR and OIOR initiated by the NS participants thus shows that the NS participants' orientation to the NNS participants' insufficient linguistic abilities through repair-initiation occurred in a highly limited range of interactional environments. In particular, the fact that the NS participants often modulated their OIOR when it occurred outside these environments suggests that the NS participants regard their orientation to the NNS participants' linguistic insufficiencies as a sensitive issue.

Lastly, with regard to the NS/NNS identity-relevant repairs, the nature of the trouble source was examined in each repair. According to the results, the NNS participants' production problems $(\mathrm{n}=66)$ and perception problems $(\mathrm{n}=64)$ became causes of speaking, hearing and understanding troubles and yielded repair sequences. ${ }^{17}$ With regard to production problems, the NNS participants mainly had difficulty finding proper expressions with which to convey their ideas $(\mathrm{n}=54,81.8 \%)$. For instance, the NNS participants had trouble choosing the correct and/or appropriate vocabulary/utterances $(n=20,30.3 \%)$, employed vocabulary/phrase checks $(n=14$, $21.2 \%$ ) because they were unsure of the adequateness of the vocabulary/phrases they were using, were unable to produce the vocabulary/phrases/utterances they needed $(\mathrm{n}=11,16.7 \%)$, and formulated nonnative-like utterances ${ }^{18}(\mathrm{n}=9,13.6 \%)$. In addition, the NNS participants had problems with the pronunciation of vocabulary items $(\mathrm{n}=6,9.1 \%)$ and grammar $(\mathrm{n}=6,9.1 \%)$. Regarding the NNS participants' perception problems, $50 \%(\mathrm{n}=32)$ were related to their phonological difficulties in perceiving the vocabulary/phrases/utterances, and the other $50 \%$ $(n=32)$ were related to their incorrect or non-understanding of the meaning of the vocabulary/phrases/utterances. Regarding the nature of the NNS participants' linguistics troubles, what is noticeable is the high occurrence of vocabulary-related problems. Specifically, vocabulary-related problems accounted for $69.7 \%(\mathrm{n}=46)$ of all production problems and $76.6 \%$ 
$(n=49)$ of all perception problems. The result of this study suggests that language learners may have opportunities to learn English vocabulary by engaging in repair practices during naturally occurring conversation.

\section{CONCLUSION}

The present study has explored the nature of the NS/NNS identities in repair practices of English conversation by adding a quantitative dimension to the conversation analysis of the relationship between NS/NNS identities and repair practice. The findings have shown that in contrast with the preoccupation with NS/NNS categories in many SLA studies of interaction (e.g., Bitchener, 1999; Færch \& Kasper, 1983; Gass \& Varonis, 1985; Long, 1983; Pica, 1987; Pica et al, 1989; Poulisse \& Bongaert, 1990; Varonis \& Gass, 1985), the participants' linguistic identities were not always relevant to explaining all their linguistic outcomes. As shown in the analyses of Excerpts 1 through 6, the participants implemented repair not only to deal with the NNS participants' language problems but also to solve interactional problems that did not come from NNS participants' linguistic insufficiencies, for example, to recall a name, to make a factual correction, or to deal with non-understanding of a technical term. Specifically, the frequency analysis showed that more than half of the repair practices (64.4\%) were irrelevant to the participants' NS/NNS identities.

Conversation analysis on NS/NNS identity-relevant repairs revealed that when the participants oriented to their linguistic identities during and through repair procedures, the NNS participants established their identities as NNSs by showing uncertainty and/or difficulties in composing their talk (e.g., Excerpt 4) or by expressing difficulties processing the NS participants' language input (e.g., Excerpt 5). Simultaneously, by directing their repair-initiation to the NS participants, thereby displaying their reliance on the NS participants to solve their language problems, the NNS participants also established the NS participants' NS identities. The NS participants constituted their NS identities by providing language solutions in response to the NNS participants' repair invitation (e.g., Excerpts 4 and 5) or by correcting the NNS participants' linguistic problems (e.g., Excerpt 6). Moreover, the NNS participants further displayed their orientation to the NS participants' NS identities by immediately taking the NS participants' solutions with repetition (e.g., Excerpt 4).

Quantitative analysis on NS/NNS identity-relevant repairs further revealed that the participants' orientation to their NS/NNS identities was mainly (65.1\%) triggered by the NNS participants' repair-initiation aimed at solving their own language problems in speaking, hearing, and/or understanding talk. At the same time, this study found that unlike in previous studies (Hosoda, 2006; Kasper, 2004; Kurhila, 2004), there were a fair number of NS/NNS identity-relevant repairs initiated by the NS participants as well. Close examination of each of the NS-initiated NS/NNS identity-relevant repairs, however, showed that the NS participants usually did so in a very limited range of interactional environments. 
With regards to the nature of the NNS participants' language troubles which led the NS and NNS participants to engage in repair work, the NS and NNS participants were usually involved in repair practices in order to deal with the NNS participants' production and perception problems with English lexical items $(69.7 . \%$ and $76.6 \%$ of the total problems, respectively). In light of focus on form studies ${ }^{19}$ (e.g., Loewen, 2005; Long, 1991; Williams, 2001), repair may function as a scaffold for English vocabulary learning.

Both the conversation-analytic and quantitative findings of the current study support those of the CA studies of the nature of the NS/NNS identities in NS-NNS interaction (Kasper, 2004; Kurhila, 2004; Hosoda, 2006; Park, 2007, etc.). Instead of being inherent or fixed categories, the NS/NNS identities had a socio-interactional and dynamic nature. The participants' NS/NNS identities were socially constructed by the participants as a result of the participants' moment-to-moment negotiation. Based on this finding, this study supports the view that when investigating NS-NNS interaction, researchers need to approach the NS/NNS identities from the participants' point of view. Otherwise, the NNS participants' linguistic outcome may be treated as a mere reflection of their NNS identities and the interactional meanings may be ignored.

The current study is meaningful in that it has provided a broad picture of the relationship between the NS/NNS identities and repair by complementing the findings of conversationanalytic research with quantitative information. ${ }^{20}$ It has also extended prior literature on the NS/NNS identities and repair by exploring the contrast between NS/NNS identity-relevant and NS/NNS identity-irrelevant repairs. On the other hand, NNS participants' differences in English proficiency were not taken into consideration in this study. In other words, how proficiency factors influence participants' orientation to their linguistic identities and repair practices were not explored. It would be worthwhile to consider proficiency factors in that the analysis may shed light on whether the language problems the NNS participants encounter during the conversation changes according to their proficiency levels. It would also be interesting to examine how the participants' orientation to their NS/NNS identities and their repair practices are shaped by contextual factors, for example in institutional contexts such as language classroom talk. Further investigations following these suggestions will add to the knowledge of NS/NNS identities and repair.

\section{ACKNOWLEDGEMENTS}

We would like to thank the anonymous reviewers for their helpful comments on earlier versions of this article. 


\section{REFERENCES}

Antaki, C., \& Widdicombe, S. (Eds.). (1998). Identities in talk. London: Sage.

Benwell, B., \& Stokoe, E. (2006). Discourse and identity. Edinburgh: Edinburgh University Press.

Bitchener, J. W. (1999). The negotiation of meaning by advanced ESL learners: The effects of individual learner factors and task type. (Unpublished doctoral dissertation). The University of Auckland, New Zealand.

Brown, A. (2003). Interview variation and the co-construction of speaking proficiency. Language Testing, 20(1), 1-25.

Carroll, D. (2000). Precision timing in novice-to-novice L2 conversations. Issues in Applied Linguistics, 11(1), 67-110.

Carroll, D. (2004). Restarts in novice turn beginnings: Disfluencies or interactional achievements? In R. Gardner \& J. Wagner (Eds.), Second language conversations (pp. 201-220). London: Continuum.

Clayman, S. E., Heritage, J., Elliott, M. N., \& McDonald, L. (2007). When does the watchdog bark? Conditions of aggressive questioning in presidential news conferences. American Sociological Review, 72(1), 23-41.

Drew, P. (1991). Asymmetries of knowledge in conversational interactions. In I. Markova \& K. Foppa (Eds.), Asymmetries in dialogue (pp. 29-48). Hemel Hamstead: Harvester/ Wheatsheaf.

Egbert, M. (2004). Other-initiated repair and membership categorization: Some conversational events that trigger linguistic and regional membership categorization. Journal of Pragmatics, 36(8), 1467-1498.

Egbert, M., Niebecker, L., \& Rezzara, S. (2004). Inside first and second language speakers' trouble in understanding. In R. Gardner \& J. Wagner (Eds.), Second language conversations (pp. 178200). London: Continuum.

Færch, C., \& Kasper, G. (1983). Plans and strategies in foreign language communication. In C. Færch \& G. Kasper (Eds.), Strategies in interlanguage communication (pp. 20-60). London: Longman

Firth, A. (1996). The discursive accomplishment of 'normality': On lingua franca English and conversation analysis. Journal of Pragmatics, 26(2), 237-259.

Firth, A., \& Wagner, J. (1997). On discourse, communication, and (some) fundamental concepts in SLA research. The Modern Language Journal, 81(3), 285-300.

Gardner, R., \& Wagner, J. (Eds.). (2004). Second language conversations. London: Continuum.

Gass, S. M., \& Varonis, E. M. (1985). Task variation and nonnative/nonnative negotiation of meaning. In S. M. Gass \& C. G. Madden (Eds.), Input in second language acquisition (pp. 149-161). Rowley, MA: Newbury House.

He, A.W. (2004) CA for SLA: Arguments from the Chinese language classroom. Modern Language Journal, 88(4), 568-582.

Heritage, J. (1984). A change of state token and aspects of its sequential placement. In J. Atkinson \& J. Heritage (Eds.), Structures in social action: Studies in conversation analysis (pp. 299-345). Cambridge: Cambridge University Press.

Heritage, J. (1999). CA at century's end: Practices of talk-in-interaction, their distributions and their outcomes. Research on Language and Social Interaction, 32(1-2), 69-76. 
Heritage, J., Boyd, E. A., \& Kleinman, L. (2001). Subverting criteria: The role of precedent in decisions to finance surgery. Sociology of Health and Illness, 23(5), 701-728.

Heritage, J., \& Maynard, D. W. (2006). Introduction: Analyzing Interaction between doctors and patients in primary care encounters. In J. Heritage \& D. W. Maynard (Eds.), Communication in medical care: Interactional between primary care physicians and patients (pp. 1-21). Cambridge: Cambridge University Press.

Hosoda, Y. (2000). Other-repair in Japanese conversation between nonnative and native speakers. Issues in Applied Linguistics, 11(1), 39-63.

Hosoda, Y. (2006). Repair and relevance of differential language expertise in second language conversations. Applied Linguistics, 27(1), 25-50.

Kasper, G. (2004). Participant orientation in conversation-for-learning. Modern Language Journal, $88(4), 551-567$.

Kurhila, S. (2004). Clients or language learners-being a second language speaker in institutional interaction. In R. Gardner \& J. Wagner (Eds.), Second language conversations (pp. 58-74). London: Continuum.

Kurhila, S. (2006). Second language interaction. Amsterdam: John Benjamins.

Lerner, G. H. (1991). On the syntax of sentences in progress. Language in Society, 20(3), 441-458.

Lerner, G. H. (2004). On the place of linguistic resources in the organization of talk-in-interaction: Grammar as action in prompting a speaker to elaborate. Research on Language and Social Interaction, 37(2), 151-184.

Loewen, S. (2005). Incidental focus on form and second language learning. Studies in Second Language Acquisition, 27(3), 361-386.

Long, M. (1983). Linguistic and conversational adjustments to non-native speakers. Studies in Second Language Acquisition, 5(2), 177-193.

Long, M. (1991). Focus on form: A design feature in language teaching methodology. In K. de Bot, R. Ginsberg, \& C. Kramsch (Eds.), Foreign language research in cross-cultural perspective (pp. 39-52). Amsterdam: Benjamins.

Mangione-Smith, R., Stivers, T., Elliott, M. N., McDonald, L., \& Heritage, J. (2003). Online commentaries during the physical examination: A communication tool for avoiding inappropriate prescribing? Social Science and Medicine, 56(2), 313-320.

Markee, N. (2004). Zones of interactional transition in ESL classes. Modern Language Journal, 88(4), 583-596.

Markee, N., \& Kasper, G. (2004). Classroom talks: An introduction. Modern Language Journal, 88(4), 491-500.

Mori, J. (2004). Negotiating sequential boundaries and learning opportunities: A case from a Japanese classroom. Modern Language Journal, 88(4), 536-550.

Ochs, E., Schegloff, E. A., \& Thompson, S. A. (Eds.). (1996). Interaction and grammar. Cambridge: Cambridge University Press.

Park, J.-E. (2007). Co-construction of nonnative speaker identity in cross-cultural interaction. Applied Linguistics, 28(3), 339-360. 
Park, J.-S. (2008). Negative yes/no question-answer sequences in conversation: grammar, action, and sequence organization. (Unpublished doctoral dissertation). University of California, Los Angeles.

Park, Y.-Y. (2004). Nonnative speakers' use of yeah in English spoken discourse. Discourse and Cognition, 11(3), 85-105.

Pavlenko, A. (2002). Poststructuralist approaches to the study of social factors in second language learning and use. In V. Cook (Ed.), Portraits of the L2 user (pp. 277-302). Clevedon, UK: Multilingual Matters.

Pennycook, A. (2001). Critical applied linguistics. Mahwah, NJ: Lawrence Erlbaum.

Pica, T. (1987). Second language acquisition, social interaction, and the classroom. Applied Linguistics, $8(1), 3-21$.

Pica, T., Holliday, L., Lewis, N., \& Morgenthaler, L. (1989). Comprehensible output as an outcome of linguistic demands on the learner. Studies in Second Language Acquisition, 11(1), 63-90.

Poulisse, N., \& Bongaerts, T. (1990, April). A closer look at the strategy of transfer. Paper presented at the 9th AILA Conference, Thessaloniki, Greece.

Rampton, B. (1995). Crossing: Language and ethnicity among adolescents. London: Longman.

Richards, J. C., \& Schmidt, R. (2010). Longman dictionary of language teaching and applied linguistics (4th ed.). Harlow: Longman.

Richards, K., \& Seedhouse, P. (2005). Applying conversation analysis. Houndsmill: Palgrave Macmillan.

Robinson, J., \& Heritage, J. (2005). The structure of patients' presenting concerns: The completion relevance of current symptoms. Social Science and Medicine, 61(2), 481-493.

Sacks, H. (1972). An initial investigation of the usability of conversational materials for doing sociology. In D. N. Sudnow (Ed.), Studies in social interaction (pp. 31-74). New York: Free Press.

Schegloff, E. A. (1988). On an actual virtual servo-mechanism for guessing bad news: A single case conjecture. Social Problems, 35(4), 442-457.

Schegloff, E.A. (1991) Reflections on talk and social structure. In D. Boden \& D. H. Zimmerman (Eds.), Talk and social structure (pp. 44-70). Cambridge: Polity.

Schegloff, E. A. (1993). Reflections on quantification in the study of conversation. Research on Language and Social Interaction, 26(1), 99-128.

Schegloff, E. A. (1997). Whose text? Whose context? Discourse \& Society, 8(2), 165-187.

Schegloff, E. A. (2007). Sequence organization in interaction: A primer in conversation analysis (Vol. 1). Cambridge: Cambridge University Press.

Schegloff, E. A. (2009). One perspective on conversation analysis: Comparative perspectives. In J. Sidnell (Ed.), Conversation analysis: comparative perspectives (pp. 357-406). Cambridge: Cambridge University Press.

Schegloff, E. A., Jefferson, G., \& Sacks, H. (1977). The preference for self-correction in the organization of repair in conversation. Language, 53(2), 362-382.

Seedhouse, P. (2004). The interactional architecture of the language classroom: A conversation analysis perspective. Malden, MA: Blackwell. 
Speer, S. A., \& Stokoe, E. (Eds.). (2011). Conversation and gender. Cambridge: Cambridge University Press.

Stivers, T., \& Majid, A. (2007). Questioning children: Interactional evidence of implicit bias in medical interviews. Social Psychology Quarterly, 70(4), 424-441.

Svennevig, J. (2008). Trying the easiest solution first in other-initiated repair. Journal of Pragmatics, 40(2), 333-348.

Varonis, E., \& S. Gass. (1985). Non-native/non-native conversations: A model for negotiation of meaning. Applied Linguistics, 6(1), 71-90.

Williams, J. (2001). The effectiveness of spontaneous attention to form. System, 29(3), 325-340.

Wong, J. (2000a). Delayed next turn repair initiation in native/non-native speaker English conversation. Applied Linguistics, 21(1). 244-267.

Wong, J. (2000b). The token "yeah" in nonnative speaker English conversation. Research on Language and Social Interaction, 33(1), 39-67.

Wong, J. (2005). Sidestepping grammar. In K. Richards \& P. Seedhouse (Eds.), Applying conversation analysis (pp. 159-173). Hampshire: Palgrave MacMillan.

Wong, J., \& Olsher. D. (2000). Reflections on conversation analysis and nonnative speaker talk: An interview with Emanuel A. Schegloff. Issues in Applied Linguistics, 11(1), 111-128.

\section{APPENDIX}

\section{TRANSCRIPTION CONVENTIONS}

(Adapted from Ochs, Schegloff, \& Thompson, 1996, pp. 461-465)

\section{TEMPORAL AND SEQUENTIAL RELATIONSHIPS}

[ a point of overlap onset

[

a point at which two overlapping utterances both end

]

$=$

If the two lines connected by the equal signs are: (1) by the same speaker, a single, continuous utterance is broken up to accommodate the placement of overlapping talk; (2) if they are by different speakers, the second follows the first with no discernable silence between them (i.e., "latched" to it).

(0.5) silence represented in tenths of a second.

(.) micropause 


\section{ASPECTS OF SPEECH DELIVERY}

falling, or final intonation, not necessarily the end of a sentence

? $\quad$ rising intonation, not necessarily a question

, "continuing" intonation, not necessarily a clause boundary

$:: \quad$ the prolongation or stretching of the sound just preceding them.

- $\quad$ a cut-off or self-interruption

word underlining indicates some form of stress or emphasis, either by increased loudness or higher pitch

WOrd upper case indicates especially loud talk

$\therefore$ The talk between the two degree signs is markedly softer than the talk around it

: $\quad$ inflected rising intonation contour

$\uparrow \quad$ sharper rises in pitch than would be indicated by combinations or colons and underlining

${ }^{\circ}$ hhh hearable inbreath

hhh hearable aspiration. It may represent breathing, laughter, etc.

(hhh) laughter occurring inside the boundaries of a word.

\section{OTHER MARKINGS}

(( )) transcriber's descriptions of events

(word) uncertainty on the transcriber's part

\section{ENDNOTES}

1 Some examples of CA studies which added quantitative methods to their research are as follows: Clayman, Heritage, Elliott, \& McDonald, 2007; Heritage, Boyd, \& Kleinman, 2001; Heritage \& Maynard, 2006; Mangione-Smith, Stivers, Elliott, McDonald, \& Heritage, 2003; Robinson \& Heritage, 2005; Stivers \& Majid, 2007.

2 Indeed, at the time of recording Eunju and Kyeongsu were good friends knowing each other for about six years, whereas Bob and Kyeongsu were mere mutual acquaintances at a local church.

3 In doing so, Hansu employs SISR in order to correct his mistake in his use of English aspect system, thereby displaying his orientation to his NNS identity. Yet, his SISR also displays his linguistic competence of monitoring and correcting one's own speech. 
In this study, the term preferred/dispreferred is not used to indicate a psychological state of an individual. Rather, it refers to systematic structural biases in the organization of talk. Normally, responses that advance and align with the action underway are preferred to those that obstruct its progressivity or disalign with it (Schegloff, 1988, 2007).

This is an instance of collaborative completion, where a recipient of a speaker's talk preemptively completes the original speaker's TCU-in-progress (Lerner, 1991, 2004). Collaborative completions were classified into the category of SIOR in this study only when the speaker of the trouble source first self-initiates repair with the use of repair initiators such as sound stretches, cut-offs, fillers, and pauses.

Some readers may pay attention to the difference between Garam's and Bob's pronunciation of the word months (i.e., monsis [m^nsis] vs. months [m^ns]) and may argue that in line 9 Bob corrects not only the length of time but also her mispronunciation. Yet, due to the following three reasons, the researchers do not regard it as a repair on Garam's pronunciation. First, Bob places a stress on the word two as indicated by the underline in the transcript, thereby displaying what is emphasized in his talk is the information on the length of time (i.e., two an' a half). Second, Bob does not put any contrastive stress on the word months nor enunciate it as in $[\mathrm{m} \wedge \mathrm{n} \theta \mathrm{s}]$. Rather he casually and unmarkedly pronounces it as [m^ns]. Third, in line 10 , Garam's response to Bob's repair does not show any evidence that she treats Bob's repair as a correction on her mispronunciation.

7 In this sense, Bob seems to provide the synonym jackets in order to help Garam to easily recognize the pronunciation of coats, presuming that Garam knows the meaning of coats.

In this subsection, excerpts are not analyzed in great detail in order to save space; for the same reason as well as to facilitate readers' understanding, previous examples are reintroduced wherever possible.

This is an instance of delayed next turn repair initiation, where other-initiation of repair is delayed within the next turn relative to the trouble source turn (Wong, 2000a). Since in line 5 a change in the speaker does not occur, Eunju's repair-initiation is located within the same turn in which her initial receipt token is, that is, the next turn position.

Excerpt 9 is an example of these cases.

11 The following excerpt shows the case in point. Prior to the interaction, Bob talked about using the word washroom in place of restroom in order to convey one's need to go to the restroom in a more euphemistic way. Yet, in line 1 after claiming her understanding of Bob's explanation with Uhuh, Dasom uses the word restroom, which triggers Bob to initiate repair on Dasom's talk by repeating the problematic word restroom twice in line 3 .

[Restaurant 1]

Dasom:

Dasom:
[ $\uparrow$ Restroom. ] $\uparrow$ Restroom.

No restroom: [(Best)] iz wa [shroom.] 
12 The three OIORs initiated by NNSs were unique cases of OIOR where the person who initiated repair directs his/her repair-initiation to the speaker of a trouble source, but some other person ends up providing a repair solution. For instance, in the following excerpt, in line 4 Jisu initiates repair on Sumi's talk in line 1 by asking Sumi what Coas' guard (coast guard), which she perceived as Coas' card, means. Yet, it is Chris who provides a repair solution by explaining its meaning (line 7).

[Restaurant 2]

13 The following excerpt is one such example. In line 2 Dasom initiates a SIOR sequence by displaying her uncertainty with the expression flower powder. In line 5 Amy provides the word Pallen (pollen) as a repair solution. However, in lines 6 and 7, Dasom displays trouble in perceiving the sound of the word pollen by pronouncing it as Paleum with the delay of a 0.4 second pause. In response to that, in line 8 Amy implements OIOR, thereby correcting Dasom's pronunciation problem.

[Photocopy Room]

$$
(0.4)
$$

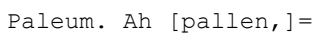


14 The excerpt below illustrates the case where Bob initiates OIOR sequence in response to Hansu's display of misunderstanding of Bob's word demonz (demons) as demand.

[Meeting Room 2]

Hansu: Uh yah. Supply an' demand.

15 Consider the following excerpt where Bob implements OIOR with a rising intonation in lines 2 and 3 .

[Meeting Room 1]

01

02

03

04

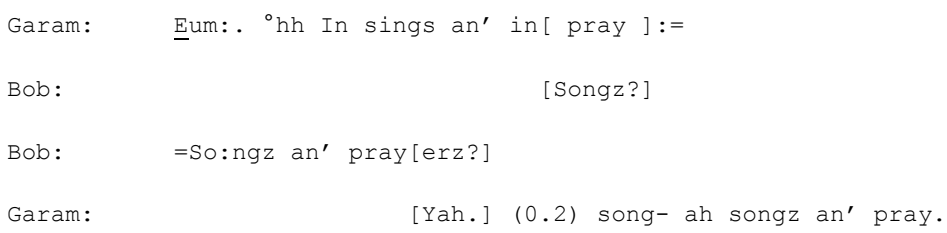

Refer to lines 2 and 4 where Chris corrects Jisu's use of the word Bread cake by providing the word Rice cake. In doing so, he first employs a rising intonation, and then, changes it into a falling intonation.

[Restaurant 2]

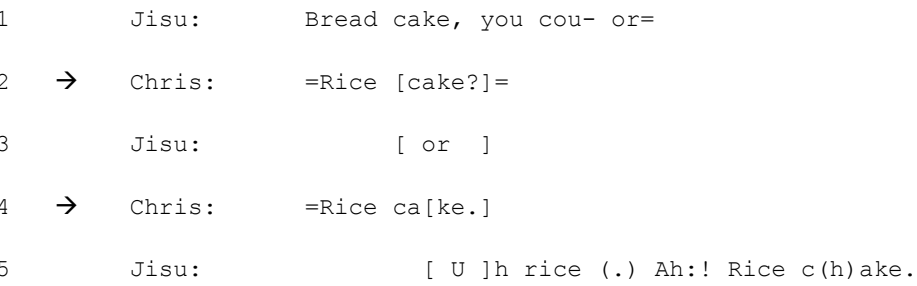

The total number of the repair operations is not equal to the sum of production and perception problems because one trouble source occasionally contained more than one category of the problem type.

8 The distinctions between vocabulary and phrases were made by reference to Richards and Schmidt (2010): single words, compound words and idioms were counted as vocabulary; 'a 
group of words which form a grammatical unit' but '[do] not contain finite verb and [do] not have a subject-predicate structure,' as a phrase (p. 81). When a trouble source consisted of a clausal part of a sentential TCU, a sentential TCU, or multiple sentential TCUs, it was regarded as utterance-related problems.

19 A focus on form 'overtly draws students' attention to linguistic elements as they arise incidentally in lessons whose overriding focus is on meaning or communication' (Long, 1991, pp. 45-46). Referring to this definition, the NS/NNS identity-relevant repairs may be considered as a type of focus on form which occurs in non-institutional conversations; by becoming involved in NS/NNS identity-relevant repairs, the NS and NNS participants explicitly pay attention to the NNS participants' linguistic problems in speaking, hearing, and/or understanding the talk.

20 Caution should be exercised, however, before generalizing the quantitative findings of the current study to other L2 data since each interactional situation may have its own unique interactional contingencies which need to be taken into account in analysis. The same point has also been raised by the analysis of ambiguous cases in this study. For this very reason, any quantitative research conducted within the framework of CA cannot dispense with careful qualitative analysis on individual cases. 